\begin{abstract}
УДК 338.222(470.61)
КОРПОРАТИВНЫЙ СЕКТОР В ПРОЦЕССАХ МОДЕРНИЗАЦИИ АГРАРНО-ИНДУСТРИАЛЬНОГО РЕГИОНА (НА ПРИМЕРЕ РОСТОВСКОЙ ОБЛАСТИ)

${ }^{1}$ Гонтарь Н.В., ${ }^{2}$ Гузенко О.И., ${ }^{2}$ Сапожникова А.Г.

${ }^{1}$ Южный федеральный университет, Ростов-на-Дону, е-mail: passat01@mail.ru;

${ }^{2}$ Донской государственный технический университет, Ростов-на-Дону,

e-mail:guzenko_post@mail.ru,ann_sapozhnikova@mail.ru

Долго- и среднесрочные факторы предопределяют актуальность поиска моделей модернизации экономики регионов РФ. В статье в качестве драйвера модернизации рассматриваются стратегии ТНК и компаний крупного бизнеса (на примере Ростовской области). Проанализированы актуальные стимулы, условия и факторы модернизации, складывающиеся в регионе. Выявлен высокий потенциал спроса, однако отсутствие добывающих отраслей, что определяет аграрно-индустриальную специализацию региона. На основании исследования стратегий спектра ключевых крупных компаний, базирующихся в области, сделан вывод об активном влиянии стратегий крупного бизнеса на такие аспекты модернизации, как инновации, инвестиции, кадровый потенциал и институты. Составляющими трендов в данных сферах стали роботизация, цифровизация производств, технологическое обновление, ориентированное на экспорт, расширение спектра продукции, организационные инновации, новые каналы продвижения продукции в России и мире. В качестве особенностей модели модернизации в регионе установлены: объединение сфер модернизации в рамках базирующихся в области ТНК, взаимодействие компаний в рамках производства, кластерный эффект, экспортные поставки ТНК, их отраслевое усложнение, комплексирование, что позволяет региону расширять экспорт и повышать технологический уровень экономики.
\end{abstract}

Ключевые слова: модернизация экономики, ТНК, региональная экономика, государственное регулирование, Ростовская область

\title{
CORPORATE SECTOR IN THE PROCESSES OF MODERNIZATION OF THE AGRARIAN-INDUSTRIAL REGION (EXAMPLE OF THE ROSTOV REGION) \\ ${ }^{1}$ Gontar N.V., ${ }^{2}$ Guzenko O.I., ${ }^{2}$ Sapozhnikova A.G. \\ ${ }^{1}$ Southern Federal University, Rostov-on-Don, e-mail: passat01@mail.ru; \\ 2Don State Technical University, Rostov-on-Don, e-mail: guzenko_post@mail.ru, ann_sapozhnikova@mail.ru
}

\begin{abstract}
Long-term and medium-term factors determine the relevance of the search for models of economic modernization in the regions of the Russian Federation. The article examines the strategies of TNCs and large business companies as a driver of modernization (on the example of the Rostov region). Analyzed the current incentives, conditions and factors of modernization developing in the region. The high potential of demand was revealed, but the absence of extractive industries, which determines the agrarian and industrial specialization of the region. Based on the study of the range of strategies of key large companies based in this area, it was concluded that the strategies of large business actively influence such aspects of modernization as innovation, investment, human resources and institutions. The components of trends in these areas are robotization, digitalization of production, export-oriented technological renewal, expansion of the product range, organizational innovations, new channels for promoting products in Russia and the world. A feature of the modernization model in the region is the integration of modernization directions within the framework of TNCs based on TNCs, cooperation of companies within the framework of production, the cluster effect, export supplies of TNCs, their sectoral complication, integration, which allows the region to expand exports and improve the technological level of the economy.
\end{abstract}

Keywords: modernization of the economy, TNC, regional economy, state regulation, Rostov region

Проблематика региональной экономической модернизации актуализируется в условиях значимых вызовов в виде долгосрочных ограничений на сырьевых рынках и структурных проблем экономики России. Среднесрочным фактором актуализации поиска драйверов модернизации стала пандемия коронавируса COVID-19, которая вызвала введение ограничений на работу ряда отраслей экономики в 2020 г. и стала фактором формирования дополнительных рисков развития регионов РФ. Согласно Счетной палате РФ, расходы на борьбу с пандемией в 2020 г. в РФ достигли 2,86 трлн руб. В 2020г. зафиксировано падение ВВП РФ на $3,1 \%$; объем государственного долга субъектов и муниципалитетов РФ на 1.02.2021 г. достиг 2,44 трлн руб. Сокращение налоговых и неналоговых доходов регионов в 2020 г. составило $2 \%$, но в регионах диверсифицированной экономики был отмечен прирост поступлений налога на прибыль (22 региона). Сбалансировать доходы регионов помогла помощь федерального центра, объем которой в 2020 г. вырос на 54 \%, до 3,8 трлн руб.

Таким образом, как долго- , так и среднесрочные факторы обуславливают поиск драйверов модернизации, понимаемой как процесс трансформации сложных социально-экономических систем в направ- 
лении адаптации к меняющимся условиям среды, что обеспечивает сохранение системы, которая в противном случае может быть разрушена в силу роста разницы потенциалов со средой. Инструментом экономической модернизации служит отраслевая и пространственная рекомбинация ресурсов и факторов развития.

Статья рассматривает рыночный сектор как драйвер модернизации, акцентируя внимание на крупных корпорациях как непосредственном акторе структурных сдвигов и рекомбинации производства. Релокация ресурсов корпорациями обеспечивается их проактивностью (превентивные действия в отношении таких вызовов, как интенсификация конкуренции, фрагментация рынков, технологические изменения, повышение требований к качеству). Проактивность означает ориентацию на результат, инициативную идентификацию и использование возможностей, превентивное действие против потенциальных угроз. С учетом роли и потенциала компаний рыночного сектора работа ориентирована на анализ их модернизационных стратегий в условиях аграрно-индустриального региона [1].

Цель исследования состоит в выявлении структурных особенностей сложившейся модели модернизационного влияния на экономику региона стратегий компаний крупного бизнеса на примере ключевого российского аграрно-индустриального региона - Ростовской области.

Исследование в качестве субъекта модернизации рассматривает крупный бизнес в системе региональной экономики. Критериями выбора компаний для анализа выступали их позиции в национальных рейтингах и структуре ТНК. Были проанализированы компании региона, входящие в рейтинг Эксперт-400, занимающие позиции системообразующих в таких отраслях, как машиностроение («АЭМ-технологии» (Атоммаш), «НЭВЗ», «Вертолеты России», «Ростсельмаш» (Новое содружество)), металлургия (ТМК, Красный котельщик), легкая про- мышленность (Глория Джинс), пищевая промышленность (Юг Руси), банки (Центринвест), сельское хозяйство (АХ «Степь»), торговля (ТД РИФ, АСТОН). Уделено внимание и стратегиям представленных в регионе иностранных ТНК. В качестве ключевых сфер модернизационных стратегий компаний исследованы сферы инноваций и НИОКР, инвестиций, образования и подготовки кадров, влияния на институты. Статистический и структурно-отраслевой анализ позволили оценить стимулы, условия и факторы модернизации.

\section{Региональная соииально-экономическая среда реализачии корпоративных модернизаичонных стратегий}

Ростовская область сегодня обеспечивает широкие поставки специализированной продукции промышленности и сельского хозяйства в регионы РФ и на мировой рынок, демонстрируя модель развития в отсутствии сырьевых отраслей. Доля региона в экономике РФ остается стабильной на протяжении 2010-2019 гг. - 1,7\% ВВП РФ, $1,84 \%$ производства в обрабатывающей промышленности. Доля в производстве продукции сельского хозяйства выросла с 4,5\% до 4,9\% в 2010-2019 гг. (табл. 1).

В 2013-2017 гг. доля региона в РФ в инвестициях составляла 1,9-2,2\%, в 2018-2019$1,5 \%$, а общая сумма инвестиций за 2010 2019 гг. достигла 1,6 трлн руб. Наблюдается усиление позиций области в ВЭД РФ: оборот внешней торговли, приходящийся на регион, возрос с 7,4 млрд долл. в 2010 г. до 12,1 в 2018 г. (11,1 млрд. - в 2019 г.).

Анализируя состояние стимулов, условий и факторов реализации модернизационного потенциала корпораций в регионе, отметим, что спрос как элемент стимулов находится на высоком уровне. Так, по численности населения (4,2 млн чел.) область находится на 6 месте в РФ. Доходы населения близки к средним по РФ: если в 20052010 гг. отношение доходов жителей региона к средним по РФ составляло 77-78\%, то в $2019-87 \%$.

Таблица 1 Динамика сравнительной структуры ВРП РФ и Ростовской области в 2010-2019 гг., \% [2]

\begin{tabular}{|c|c|c|c|c|c|c|}
\hline Территория & $\begin{array}{c}\text { Сельское } \\
\text { хозяйство }\end{array}$ & $\begin{array}{c}\text { Добывающие } \\
\text { отрасли }\end{array}$ & $\begin{array}{c}\text { Обрабатывающая } \\
\text { промышленность }\end{array}$ & Строительство & Торговля & $\begin{array}{c}\text { Транспорт } \\
\text { и связь }\end{array}$ \\
\hline \multicolumn{7}{|c|}{2010 г. } \\
\hline РФ & 4,2 & 10,5 & 17,7 & 6,9 & 19,3 & 10,5 \\
\hline Ростовская обл. & 11,6 & 0,9 & 19,4 & 8,5 & 18,1 & 10,4 \\
\hline \multicolumn{7}{|c|}{2019 г. } \\
\hline РФ & 4,3 & 14,8 & 18,0 & 5,6 & 15,8 & 7,6 \\
\hline Ростовская обл. & 10,2 & 1,2 & 20,9 & 5,7 & 17,8 & 7,8 \\
\hline
\end{tabular}


Условия модернизации, которые формируются институциональной средой в регионе и политикой системы управления, включают формирование промышленных зон, которые предоставляют облегченный режим регистрации компаниям и содействие в инфраструктурной подготовке территории. В институциональном поле был создан ряд механизмов развития, таких как Агентство инвестиционного развития, механизм «100 губернаторских инвестиционных проектов». Примерами институциональной поддержки стали, например, включение проекта «Эйр Продактс» В «Губернаторскую сотню»; субсидия на возмещение части затрат на подключение к сетям электро- и газоснабжения в сумме 28,9 млн руб. для завода «Гардиан» в 2012 г. При участии АИР привлечены десятки производственных компаний, актуальный портфель проектов имеет объем более 152 млрд руб. до 2024 г. Важнейшими факторами развития крупного бизнеса в регионе и его модернизационной активности являются приморское положение, портовые отгрузочные мощности, климат как основа аграрного производства, значительные трудовые ресурсы, исследовательская база НИИ и университетов.

\section{Модернизачия ключевых сфер экономики Ростовской области в стратегиях корпорациий}

В качестве ключевых векторов региональной модернизации, реализуемых корпорациями, локализованными в области, рассматриваются инновационные и инвестиционные проекты, а также участие компаний в образовательных проектах в регионе, влияние на институциональную среду (законодательство и практики бизнеса). Взаимосвязанные инновационные и инвестиционные проекты направлены на обеспечение рыночного позиционирования компаний и рост эффективности, выход на внешние рынки, что формирует долгосрочную устойчивость прибыли, налоговой базы и занятости (табл. 2).

Ввиду стратегической значимости ряда предприятий области и их экспорта, государство содействует реализации инвестиционных приоритетов компаний региона. Так, для «Вертолетов России» актуальны субсидирование производства запчастей, субсидирование процентов по кредитам, субсидирование затрат, связанных с прохождением сертификации (приборов и агрегатов). Также речь идет и о субсидировании процентных ставок по кредитам для поставки на экспорт (совместно с ВЭБом). Такая поддержка касается производителей самолетов, вертолетов, тепловозов, иннова- ционных вагонов, высокотехнологичной промышленной продукции. «Вертолеть России» ориентированы, помимо реализации национальных проектов (поставки для Национальной службы санитарной авиации и использование «Ансат» для корпоративных перевозок), на внешние рынки (контракты на поставку 20 «Ансат» в интересах Ассоциации медицины катастроф КНР и 50 мягких заказов на Ми-171А2 и «Ансат» для стран ЮВА).

Сегодня пример эффективных внешних поставок демонстрирует «АЭМ-технологии», который ведет переговоры по поставкам сменяемого оборудования для ремонта АЭС в Европе. Для ТМК доля экспорта составляет более $20 \%$ от объема продукции; кроме труб на экспорт стала поставляться заготовка для трубного и машиностроительного сектора.

Образование и подготовка кадров являются неотъемлемыми элементами стратегий корпораций в области, обеспечивая рост качества человеческого капитала и кадровый резерв самих компаний. Так, ЦентрИнвест еще в 2013 г. запустил онлайн-проект «Предпринимательский всеобуч», где школьники смогли изучить основы предпринимательства и экономики. Ежегодно свыше 2 тыс. чел. участвуют в конкурсе банка «Умная стипендия» в региональных вузах, а около 500 чел. проходят курс банковского дела. «АЭМ-технологии» как высокотехнологичное производство занимается обучением и аттестацией кадров в собственном учебном центре, отраслевом центре профессиональных компетенций «Сварочные технологии». На базе «Атоммаша» создан и ресурсный центр, где иностранные студенты - будущие атомщики - проходят практику. «НЭВЗ» для компенсации дефицита квалифицированных кадров взаимодействует с вузами Новочеркасска и Ростова-на-Дону, развивая также собственный корпоративный учебный центр.

TМК (ПАО «ТАГМЕТ»), в свою очередь, поддерживает молодых специалистов, в том числе субсидируя им съем жилья, а также проценты по ипотеке. Наряду с этим ТМК развивает и Корпоративный университет TMК2U со штаб-квартирой в Сколково. В Донском государственном техническом университете (ДГТУ) компании выделяется до 10 бюджетных мест, ориентированных на трудоустройство на ТМК.

Компания Ростсельмаш участвует в реализации федерального проекта «Кадры для отрасли» (привлечение выпускников через взаимодействие с образовательными организациями). Специалисты предприятия участвуют в разработке и реализации 
образовательных программ, в том числе в ДГТУ [9]. Кроме того, с 2012 г. на базе Ростсельмаша функционирует Учебный центр, с 2015 г. - Академия Ростсельмаш, где готовят специалистов технических центров. В учебных заведениях открываются учебные классы компании. Благодаря федеральной программе «Образование» Ростсельмаш совместно с дилерами оборудовал более 100 специализированных лабораторий в аграрных вузах и ссузах. $A X$ «CTEПЬ» реализует проект «Школа цифровых навыков» в рамках российского образовательного проекта «Лифт в будущее. 3.0» для школьников, студентов и молодых ученых.
Сфера формирования институцчиональной среды является областью контактов компаний региона и системы управления. Так, «Центр-Инвест» участвует в обсуждении цифровизации, проектах регуляторов и инициативных законотворческих группах, работе Ассоциации банков «Россия», где обсуждаются регуляторные изменения. Компонентом развития в области практик бизнеса является внедрение ТНК (в том числе зарубежными) стандартов производства, которые стандартизируют качество и позволяют капитализировать производство местных компаний посредством поставок крупным производителям.

Таблица 2

Модернизационные векторы деятельности корпораций в Ростовской области в инновационной и инвестиционной сфере

\begin{tabular}{|c|c|}
\hline $\begin{array}{c}\text { Вектор } \\
\text { модернизации }\end{array}$ & Отражение в стратегиях компаний \\
\hline $\begin{array}{c}\text { Рост эффективно- } \\
\text { сти производствен- } \\
\text { ного комплекса }\end{array}$ & $\begin{array}{l}\text { «ентр-Инвест»- внедрение дистанционного обслуживания компаний, персо- } \\
\text { нификация услуг. Программа «Трансформация бизнеса» для ускорения оциф- } \\
\text { ровки бизнес-процессов, перехода в онлайн-формат, создания дистанционного } \\
\text { управления бизнесом, что содействует росту адаптивности компаний [3]. } \\
\text { «АЭМ-технологии» (Атоммаш) - внедрение программы Plant Simulation } \\
\text { для оцифровки производственных процессов, станков и агрегатов, производи- } \\
\text { мого оборудования. Цель программы - формирование «умной» сети [4]. Приме- } \\
\text { нение системы 5S. Для наглядного представления о задержках в материальном } \\
\text { и информационном потоке - картирование потока создания ценности (VSM), } \\
\text { анализ факторов, увеличивающих время протекания процессов производства; } \\
\text { организационный инструмент (SMED); инструмент TPM для организации } \\
\text { и проведения технического обслуживания и ремонта оборудования, Система JIT } \\
\text { (Јust-In-Тіmе) для снижения количества запасов. } \\
\text { TMК - трансформация бизнеса с помощью цифровизации ключевых процессов }\end{array}$ \\
\hline $\begin{array}{c}\text { Расширение } \\
\text { спектра продукции } \\
\text { и мощностей } \\
\text { производств }\end{array}$ & 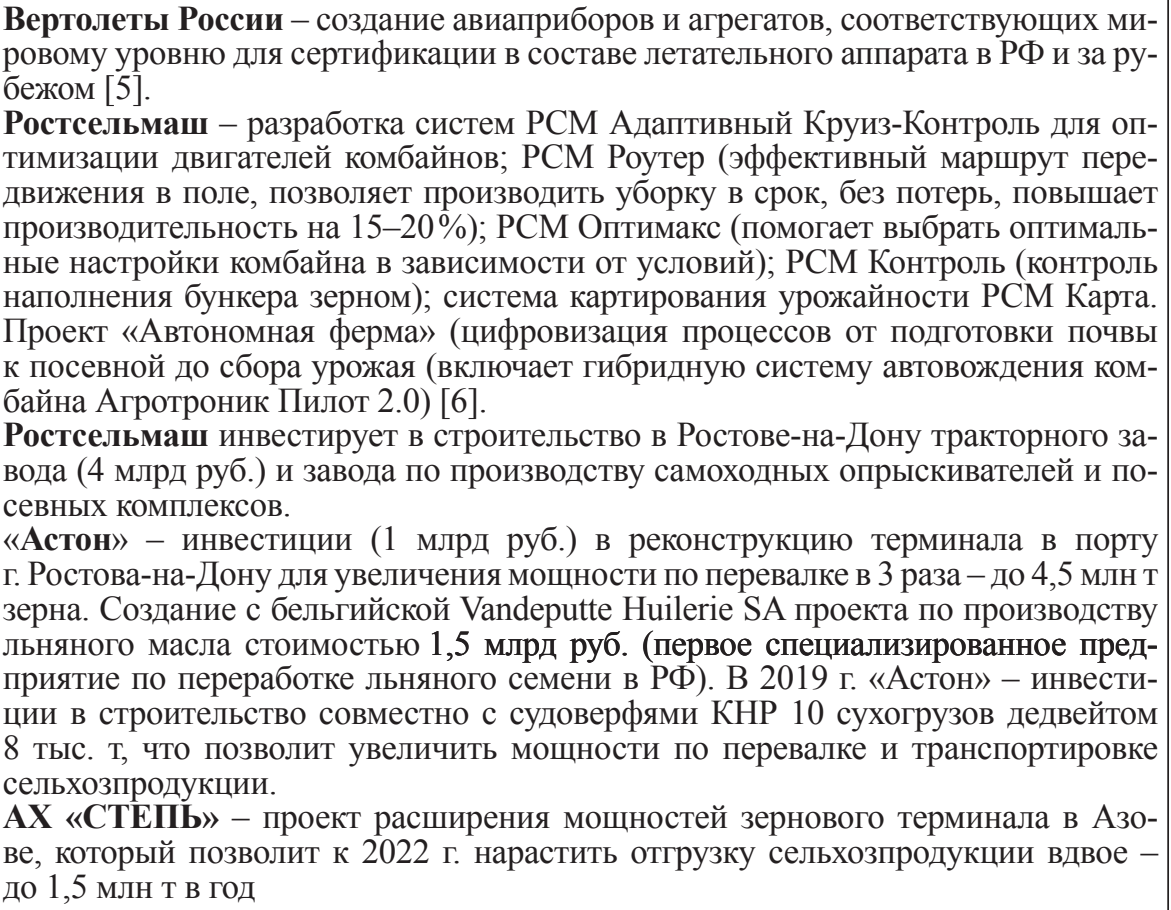 \\
\hline
\end{tabular}




\begin{tabular}{|c|c|}
\hline & Окончание табл. 2 \\
\hline $\begin{array}{c}\text { Вектор } \\
\text { модернизации }\end{array}$ & Отражение в стратегиях компаний \\
\hline $\begin{array}{l}\text { Повышение техно- } \\
\text { логического уров- } \\
\text { ня производств }\end{array}$ & 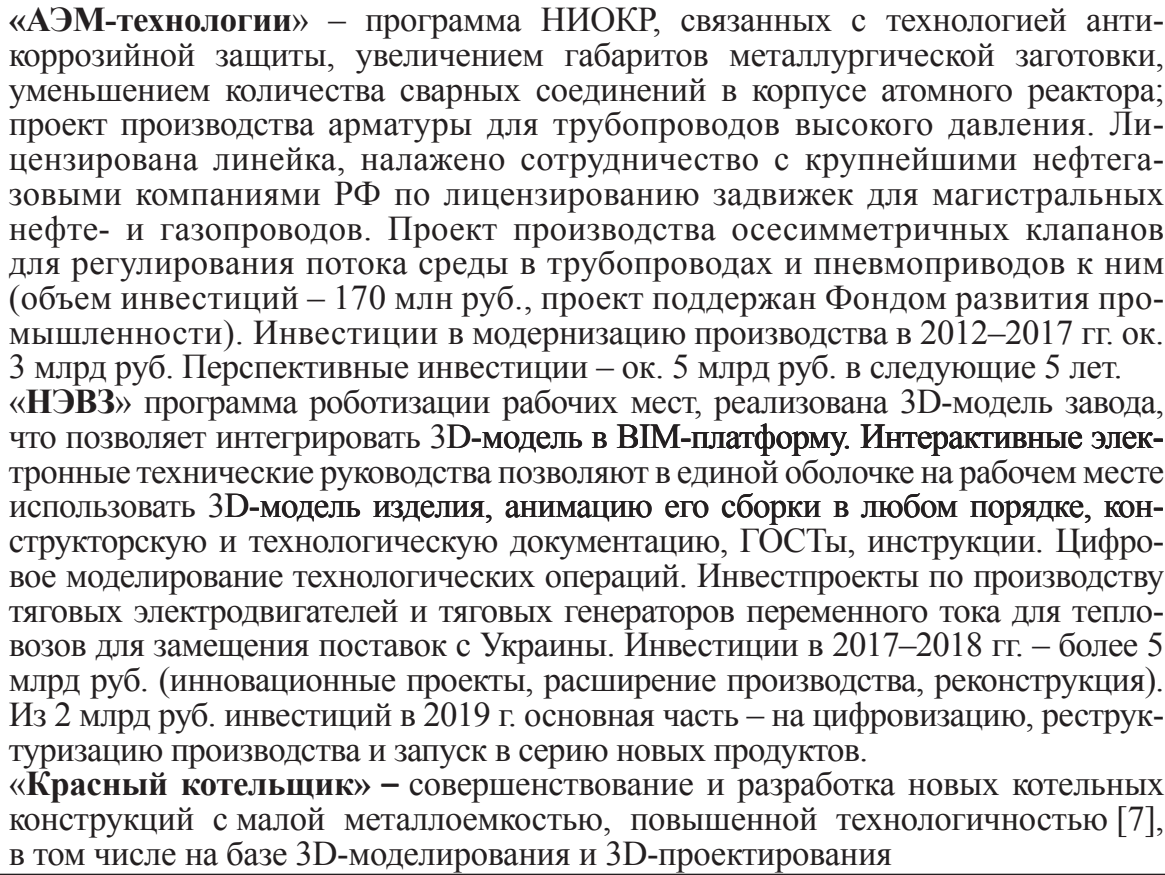 \\
\hline $\begin{array}{c}\text { Продвижение } \\
\text { продукции }\end{array}$ & $\begin{array}{l}\text { «Глория Джинс»- интернет-технологии продвижения через интернет-магазин } \\
\text { и маркетплейсы (планируется рост объема продаж через интернет в 12,5 раза, } \\
\text { до } 2 \text { млрд руб. [8]). Агроходлинг «Юг Руси»- инновационные интернет-кан-- } \\
\text { лы продажи готовой брендированной продукции }\end{array}$ \\
\hline $\begin{array}{l}\text { Повышение } \\
\text { эффективности } \\
\text { организации } \\
\text { производства }\end{array}$ & $\begin{array}{l}\text { НЭВ3 - развитие производственной системы (сегментация заготовительного, } \\
\text { электромашинного и аппаратного производств, подготовка к выводу на аутсор- } \\
\text { синг непрофильных направлений, организация ритмичной работы основных } \\
\text { сборочных линий. Реструктуризация включает три направления: повышение } \\
\text { мощностей электромашинного производства (задача - выйти на объём вып-- } \\
\text { ска в } 4 \text { тыс. тяговых электродвигателей в год; выпуск в } 2018 \text { г. г. - ок. } 3 \text { тыс.); } \\
\text { создание централизованного заготовительного производства; организация рит- } \\
\text { мичной работы линии сборки (двухсекционный электровоз должен выходить } \\
\text { из сборочного цеха каждые } 16 \text { часов) }\end{array}$ \\
\hline
\end{tabular}

\section{Эффект интеграчии и диверсификаиии корпоративного сектора для формирования модернизаиионных векторов}

Модель модернизации в экономике области опирается на её многопрофильность, в том числе в силу локализации иностранных ТНК, реализовавших как greenfield(PepsiCo, Coca-Cola HBC, Guardian, IKEA, Leroy Merlin, Metro), так и brownfield проекты (например, Alcoa в Белой Калитве). Элементами модернизационной модели в рамках многоотраслевого комплекса являются:

- сопряжение сфер модернизации в рамках самих ТНК, в частности в силу одновременных инвестиций в инновации, НИКОР, подготовку кадров;

- взаимодействие крупнейших компаний в рамках производственных цепочек и межотраслевых связей. Так, АПК является ключевой сферой взаимодействия компаний машиностроения (Ростсельмаш), переработки (Юг Руси, РеpsiCo), экспорта (зерновые терминалы Louis Dreyfus Company (LDC), «Астон», AX «Степь»);

- вовлечение в изготовление конечной продукции местных поставщиков (около $30 \%$ поставщиков картофеля для азовского завода РеpsiCo - предприятия области) [10]. К 2015 г. 95 \% сырья и материалов для СосаCola Hellenic были закуплены у поставщиков из РФ [11];

- кластеризация на основе профильных видов производства, наиболее явным примером которой является сфера АПК. Так, наряду с производителями продукции АПК, в регионе локализовали мощности крупные производители упаковки (Атлантис-Пак, Segezha Group); 
- расширение деятельности ТНК в области в отраслевом измерении: так, завод $\mathrm{Air}$ Products, начав производство промышленных газов, приступил и к созданию современного судостроительного-судоремонтного комплекса на Азовском море. Появление новых статей экспорта из региона (промышленных газов Air Products, флоат-стекла Guardian и других) повлекло развитие фирм-спутников: так, завод GUARDIAN сотрудничает более чем с 300 локальными компаниями [12];

- опора на региональную образовательную и исследовательскую среду. Так, ДГТУ находится в тесном взаимодействии с Ростсельмашем и Роствертолом; аграрное производство взаимодействует с НИИ, локализованными в области (Ростовский аграрный научный центр, НИИ мелиорации, ВНИИ виноградарства и виноделия).

Связи ТНК с местными производителями имеют модернизационные векторы в силу того, что обрабатывающие производства придают импульс местным производителям в области производства, инвестиций, знаний и поступления доходов. Технологичность российских и иностранных ТНК в области позволяет избегать таких рисков ПИИ, как усиление традиционных сравнительных преимуществ (природные ресурсы, дешевая рабочая сила). Отсутствуют и чрезмерные льготы для ТНК, которые бы снижали эффект их привлечения.

\section{Заключение}

Таким образом, модель участия крупнейших несырьевых российских компаний и иностранных ТНК в модернизации экономики Ростовской области характеризуется развитием производственно-технологического, кадрового и научно-образовательного потенциала, опорой на отрасли всероссийской специализации (комбайны, вертолеты, электровозы, оборудование атомной промышленности), вовлечением корпораций в ключевые процессы модернизации. Важными следствиями многоотраслевого развития служат кластерный эффект, по- явление бизнесов-смежников, расширение деятельности ТНК, расширение экспорта.

\section{Список литературы}

1. Гонтарь Н.В., Гузенко О.И., Сапожникова А.Г. Стратегии модернизации экономики регионов России на основе проактивного и интеграционного потенциала корпоративного сектора. Ростов-на-Дону; Таганрог: Изд-во ЮФУ, 2020. $224 \mathrm{c}$

2. Регионы России [Электронный ресурс]. URL: https:// rosstat.gov.ru/folder/210/document/13204 (дата обращения: 11.03.2021)

3. Высоков В. Проблема не в том, откуда выйти, проблема в том, куда войти. [Электронный ресурс]. URL: https:/vysokov.ru/interviu/intervyu-v-pechatnyix-smi/vasilijvyisokov- \%C2 \%ABproblema-ne-v-tom,-otkuda-vyijti,problema-v-tom,-kuda-vojti \%C2\%BB.html (дата обращения: 11.03.2021).

4. Контролируемая реакция: как развивается «Атоммаш». Интервью генерального директора «АЭМтехнологии» Игоря Котова / Атомная энергия [Электронный pecypc]. URL: https://www.atomic-energy.ru/ interviews/2019/06/21/95617 (дата обращения: 11.03.2021)

5. Программа инновационного развития холдинга «Вертолеты России» [Электронный ресурс]. URL: https:// www.russianhelicopters.aero/uploads/reports/innovation/ $\%$ D0 \%9F \%D0 \%94-20-010\%20\%D0 \%BE \%D1 \%82\%20 26.02.2020.pdf (дата обращения: 11.03.2021).

6. Тамагут П. Конкуренщия за «мозг» агропредприятий [Электронный ресурc]. URL: https://expertsouth.ru/ articles/konkurentsiya-za-mozg-agropredpriyatiy (дата обращения: 11.03.2021)

7. Инновации в трех измерениях: 3D-моделирование на заводе «Красный котельщик». /Управление производством [Электронный ресурc]. URL: http://www.up-pro.ru/ library/information_systems/project/3dmodel-kotelshik.html (дата обращения: 11.03.2021).

8. Кононова Л., Дудник Т., Строителев С. «Глория Джинс» увеличит продажи онлайн в 12 раз [Электронный pecypc]. URL: https://gorodn.ru/razdel/novosti_kompaniy/ situatsiya_na_krupnykh_donskikh_predpriyatiyakh/29929/ (дата обращения: 11.03.2021).

9. Ростсельмаш. Образовательные программы [Электронный ресурс]. URL: https://careers.rostselmash.com/ programs/ (дата обращения: 11.03.2021).

10. Новые планы PepsiCo в Ростовской области. https:// www.donland.ru/news/5218/ 17.06.2019 (дата обращения: 11.03.2021)

11. Coca-Cola Hellenic увеличивает инвестиции в свой проект в Ростовской области https://rosng.ru/post/content/ content-coca-cola-hellenic-uvelichivaet-investicii-v-svoyproekt-v-rostovskoy-oblasti?page $=44 \&$ per-page=1. (дата обращения: 11.03.2021)

12. Завод GUARDIAN в Ростовской области отгрузил первое товарное стекло // https://www.ipa-don.ru/ news/2012/12/288 (дата обращения: 11.03.2021). 